\title{
A CAMEL DRIVER IN THE ACHAEMENID PERSIAN EMPIRE: SOCIAL NETWORK ANALYSIS OF A NON-ELITE PROFESSIONAL AND THE PERSEPOLIS FORTIFICATION ARCHIVE*
}

\author{
J. TROY SAMUELS
}

\section{Introduction}

Social network analysis is a rapidly expanding field for interpreting the interplay of relationships in the past. Scholars of the ancient Mediterranean and Near East have experimented with technologies of network analysis in attempts to approach numerous historical and archaeological questions from a new perspective. However, due to the fragmentary nature of our data, the complexities of past social interactions remain elusive. The evidence available in many of these social network analyses is seldom fine-grained enough to represent individual human actions; the data sets are constantly in need of manipulation, reconstruction, and speculation. With these caveats in mind, however, the sealed and dated imperial administrative documents of the Persepolis Fortification archive (509-493 BCE in the reign of Darius I of the Achaemenid Persian Empire) present an opportunity to study individuals with a rare degree of textual and visual information and detail. Moreover, it is possible to glimpse interactions among a variety of social groups beyond the narrow elite that is already well represented in many of our literary and archaeological sources.

The aim of this paper is twofold: first, to demonstrate the utility of a social network approach for exploring the complex data set of the Persepolis Fortification archive; and second, to display the potential of this analytical tool for understanding social life in the Persian Empire below the level of the highest elites of the court. The paper thus embraces numerous non-elites who were the beating heart driving this impressive, evolving, imperial system of vast geographical expanse and multicultural complexity. ${ }^{1}$ Dakizidda, a camel

\footnotetext{
* I would like to thank the editors of this BICS themed issue and the two anonymous reviewers for their thoughtful and constructive readings which improved an earlier version of this paper. Further thanks are owed to the programmers, sponsors, and contributors of the free software, tutorials, and forums related to Gephi, and everyone who read or commented on written and oral drafts of this paper, in particular Sabina Ion for her insight and patience. Special thanks to Mark B. Garrison for providing access to his database of seal images. Finally, I owe a depth of gratitude to Margaret Cool Root. She provided the inspiration to pursue this project, an incredible amount of help and conversation in the writing of this paper, and provided feedback and insight that significantly improved the final product. All mistakes throughout remain my own.
}

${ }^{1}$ I use the term non-elite here intentionally to encompass the flexible category of people who are not part of the uppermost echelons of the Persian court in Persepolis. All of these individuals are certainly not of the lowest classes and some could be quite well off, yet they are operating at different levels of the social hierarchy to Darius and his court. While other terms (poor, peasant, middle class) were considered, they were either too restrictive (peasant), not applicable (poor), or carried far too much modern baggage (middle class). 'Non-elite' was chosen as 


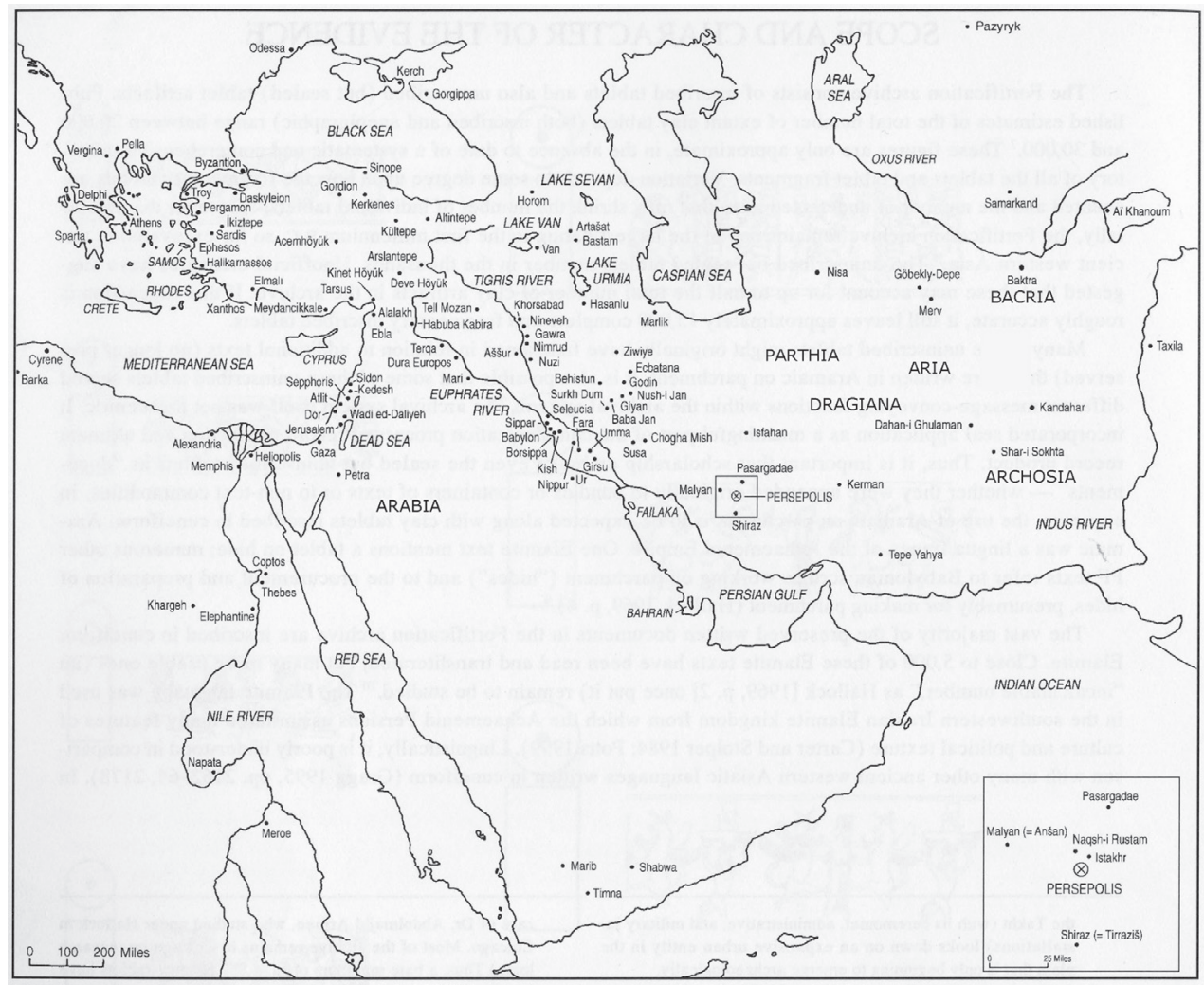

Figure 1: Map of the Achaemenid Persian Empire and its world. Adapted from Seals of Heroic Encounter, ed. Garrison and Root 2001 (n. 11) 4. Figure courtesy of M. C. Root.

driver, will serve as a case study, exhibiting how social network analysis can reconstruct the world of just the type of non-elite individual who tends to elude us in our studies of antiquity.

\section{The Persepolis Fortification archive}

The Persepolis Fortification archive is one of the richest documentary sources for the study of Achaemenid history, detailing an empire that stretched over an immense geographic extent, from the Indus Valley to the Aegean Sea, from the Persian Gulf to the first cataract of the Nile (Figure 1). ${ }^{2}$ The tablets of this large archive were discovered in office rooms within the casemate fortification wall at the northeastern corner of the Persepolis citadel (the Takht) by an Oriental Institute expedition led by Ernst Herzfeld in the spring of $1933 .^{3}$

an inclusive term (encompassing a significant subset of the population of Persepolis) and a means of consciously contrasting this large and important group with the 'elites' (i.e. the king, members of the royal family, nobles, and particularly distinguished courtiers/administrators) who figure prominently in historical narratives about the Persian court produced by classical authors.

${ }^{2}$ P. Briant, From Cyrus to Alexander. A history of the Persian Empire, trans. P. T. Daniels (Winona Lake 2002$) 1$.

${ }^{3}$ M. B. Garrison and M. C. Root, Seals on the Persepolis Fortification Tablets. Volume I. Images of Heroic Encounter, Oriental Institute Publications 117, text and plate vols (Chicago 2001) 23-29, on the serendipitous discovery; R. T. Hallock, Persepolis Fortification Tablets, Oriental Institute Publications 92 (Chicago 1969). 
The sheer number of tablets is immense, with recent estimates placing the total number of tablets at about $20,000 .{ }^{4}$ The information in this archive is likewise quite significant. The tablets represent a 'time slice' of the administrative 'paperwork' from the Achaemenid capital at Persepolis and its hinterland, an area roughly corresponding to the modern southwest Iranian region of Fārs. One of the administrative capitals of the Achaemenid monarchs, as well as its ceremonial centre, Persepolis was a location of great significance for the Achaemenid Empire and its court.

The tablets date to the regnal years thirteen to twenty-eight of Darius I (the Great). They primarily detail the complex system for the transport, receipt, taxation, storage, and redistribution of locally produced foodstuffs, commodities, and livestock. The particular historical moment the tablets reveal follows Darius' reconquest of Egypt when Achaemenid power was waxing towards its zenith, the Persepolis citadel had just been built, its artistic elaboration with works of art such as the great Apadana reliefs was underway, and, on an empire-wide level, programs of imperial control, both artistic and administrative, were crystallizing. These systems of empire that proved influential to Alexander the Great, the Romans, and beyond were beginning to solidify. The tablets recovered are surely only a part of a more extensive archive; indeed, systematic excavations of other rooms in the casemate wall to potentially expand the archive have not yet been undertaken.

The evidence for this paper is drawn primarily from the 2,087 Elamite administrative tablets published in transliteration and English translation by Richard T. Hallock, which form the subsequent research corpus of the three-volume seal study initiated with Volume I in 2001 by Mark B. Garrison and Margaret Cool Root. ${ }^{5}$ Hallock's sample of published tablets (isolated after decades of effort) was deliberately intended to represent the full range of text types found in this administrative system, from terse receipts to extended accounts in 'letter' form. ${ }^{6}$

While these tablets cover a compressed timeline and a somewhat limited geography given the context (the Persepolis geographic region was expansive in its own right), it should not be imagined that Darius' administrative and disbursement apparatus sprang fully formed from nothing at his reign's inception and disappeared into the desert upon his death. Similar archival systems are implied in ancient authors such as Xenophon and Herodotus and are likely to have been in place at other Achaemenid capitals (both satrapal and royal). The existence of travel receipts at Persepolis (Hallock's 'category Q') also implies the presence of similar documentation at the various warehouses that supplied this exchange system. These further archives were either recorded on perishable material, have not survived, or have yet to be excavated. Isolated finds of Elamite language tablets at Susa in southwest Iran and Old Kandahar in Bactria (modern Pakistan) at the eastern and western fringes of the Achaemenid military-political dominion support this wider network of PF-like

\footnotetext{
${ }^{4}$ See C. E. Jones and M. Stolper, 'How many Persepolis Fortification tablets are there?', in L'archive des Fortifications de Persépolis. État des questions et perspectives de recherches, ed. P. Briant, W. Henkelman, and M. Stoper (Paris 2008) 27-50 for a full discussion of the tablet count.

${ }^{5}$ See Garrison and Root, Seals on the Persepolis Fortification Tablets Volume I (n. 3, above) 3, 1-7. PF corpus refers to the entire body of data embraced by the PF tablets, their texts, and their seals. PF as a prefix before a numeral refers to a specific PF tablet.

${ }^{6}$ M. C. Root, 'The legible image: how did seals and sealing matter in Persepolis?', in L'archive des Fortifications de Persépolis. État des questions et perspectives de recherches, ed. P. Briant, W. Henkelman, and M. Stoper (Paris 2008) 88 .
} 
disbursement archives. ${ }^{7}$ The archive from Persepolis can therefore be seen as an example of the multifaceted body of data one might expect to find in different variations across the Achaemenid world; it is a guide for the form and content of these various archives. While local variations must be taken into account, the social relations we can isolate at Persepolis likely followed similar patterns across the temporal and spatial extents of Achaemenid imperial rule.

In recent years the Oriental Institute of the University of Chicago has engaged in a massive campaign to edit (if not necessarily to translate for widespread documentary access) the remaining tablets both in Elamite and in Aramaic and to inventory, draw, and catalogue the seals - which appear on the inscribed tablets and also on tablets which do not bear inscriptions in any language — not already included in the Garrison and Root research corpus. ${ }^{8}$ One of the strengths of social network analysis is that, as more tablets are published (complete with texts and seal apparatus), they can easily be incorporated into my networks. The sample of tablets from Hallock's 1969 text corpus represents a significant volume of data, large enough to work with in quantitative analytical terms.

\section{The tablets, their texts, and their seals}

Hallock divided the PF tablets into numerous lettered categories, but in one format or another all pertain to commodity allocations, disbursements, or storage within the Persepolis regional administrative system and all conform to relatively generic formulae. ${ }^{9}$ Take for example PF 1787, a text from Hallock's S3 'travel rations for animals' category. Hallock's translations read:

PF 1787: 9.9 BAR (of) flour, supplied by Karma, Bawukšamira received, (for) rations (of) thirty-three camels of the king. He carried a sealed document of Parnaka. He went to the king (at) Susa. First (Elamite) month, twenty-second year. ${ }^{10}$

This text is rich with data: it explicitly states (1) the goods disbursed in the Persepolis administrative system (flour); (2) the name of the supplier of the flour (Karma); (3) the amount of goods supplied (9.9 BAR); ${ }^{11}$ the name of the person who received the flour (Bawukšamira); (5) the movement of Bawukšamira (westward to the king who was currently at Susa); (6) the name of the individual on whose authority the sealed document was being

\footnotetext{
${ }^{7}$ Xen An. 1.2.20, Hdt. III.128, Briant, From Cyrus to Alexander (n. 2, above). See Garrison and Root, Seals on the Persepolis Fortification Tablets Volume I (n. 3, above) 9 for discussion of the size of the Persepolis administrative region and 32 for the discussion of PF-like archives in other areas under Achaemenid purview.

${ }^{8}$ In this article, PF corpus refers specifically to the corpus of tablets and seals published by Hallock in 1969 and (for the seals) by Garrison and Root in 2001 and forthcoming (volumes II and III). The prefix PF before a tablet number refers (by scholarly convention) specifically to the selection of tablets inscribed in Elamite that were published by Hallock in 1969. The prefix PFS before a seal number refers to seals occurring not only on the Hallock 1969 subset of all the Elamite tablets but also on newly inventoried/edited Elamite tablets — as these are either attached as new occurrences to existing PFS numbers in the Garrison and Root corpus or are given new numbers because they do not replicate a seal already known from that corpus. For a recent study looking at the entire archive including seals on the Aramaic and uninscribed tablets see L'archive des Fortifications de Persépolis. État des questions et perspectives de recherches, ed. P. Briant, W. Henkelman, and W. Stolper (Paris 2008).

${ }^{9}$ Hallock, Persepolis Fortification Tablets (n. 3, above) 13-57.

${ }^{10}$ Following Hallock, Persepolis Fortification Tablets (n. 3, above) 486.

${ }^{11}$ BAR is a measure for solid liquid goods respectively. 10 QA equals 1 BAR. See Hallock, Persepolis Fortification Tablets (n. 3, above) 72-74.
} 
sent via Bawakšamira to the king (Parnaka — head administrator of Persepolis and member of the royal family); (7) the function of the goods (camel rations), and (8) the date of the disbursement (first Elamite month in the twenty-second regnal year of Darius, or 500 BCE). Furthermore, the name of the flour supplier (Karma) can be linked irrefutably to a specific seal (PFS 21) applied to (that is, impressed upon) the tablet's left edge according to a wellunderstood sealing protocol for travel rations in the archive. ${ }^{12}$ Each piece of information (textual and visual) provided on a tablet can be included in a social network analysis and allows for a variety of visual representations and mathematical analyses. While not every tablet contains as much or the same information as PF 1787, the amount of data is typically substantial.

As PF 1787 demonstrates, the textual and visual data of seals applied to a given tablet interlock across the archive. While the tablets are not all sealed, the vast majority of the tablets do bear impressions of between one and four seals, with two being the norm and six being the highest number. ${ }^{13}$ Again, the sheer number of seals is significant: approximately 1,160 analytically legible discrete seals yielding many thousands of impressions have been identified in the Garrison and Root research corpus alone. ${ }^{14}$ The occurrences of so many of these seals in multiple tablet contexts in the archive enhances the quantitative significance of these data exponentially. When the seals from the other tablets excavated by Herzfeld are taken into account, Garrison has stated that, 'the total number of images on all the excavated tablets [in the entire Persepolis Fortification archive] may represent one of the largest collections of visual imagery from the ancient world. ${ }^{15}$ Just like the texts with which they are used in association, the individual seals contain a wealth of information that can be examined using social network analysis.

The attribution of these seals to the individuals named in the texts on the tablets is not always straightforward. Some seals represent an office, not an individual; the same individual may occasionally use more than one seal, or the sealing protocols on a particular text-type may remain difficult for us to understand fully. Nevertheless, the connection between specific seals applied to the tablets and the specific individuals named in the associated texts can usually be made. ${ }^{16}$ In these many instances when an association is clear,

\footnotetext{
${ }^{12}$ Karma's seal, PFS 21, appears on numerous tablets where Karma is named and identified as a supplier (PF 423, PF 783, PF 826, PF 1011, PF 1044, PF 1080, PF 1262, PF 1337, PF 1338, PF 1340, PF 1341, PF 1342, PF 1343, PF 1344, PF 1677, PF 1703, PF 1711, and PF 1787). PFS 21 displays a highly distinctive archer hunt scene in the Fortification Style, to be published in vol. II of Garrison and Root, Seals on the Persepolis Fortification Tablets (forthcoming). On three PF tablets Karma's name and function appear in the text without the application of his seal: PF 423, PF 783, and PF 826. The fact that PFS 21 does not appear on these tablets, in addition to the cooccurrence of seals (see below), was the basis for constructing my network. Despite the naming of Parnaka, I did not include PF 423, PF 783, and PF 826 in my network; a complete prosopographical study linking names as well as seals would be needed to justify their inclusion and is one possible avenue of future research.

${ }^{13}$ Garrison and Root gave each individual seal that occurs on the tablets a discrete PFS (Persepolis Fortification Seal) number. The seal numbers used in Hallock 1969 are no longer current. See Garrison and Root, Seals on the Persepolis Fortification Tablets (n. 3, above) 44-46. The letter 's' following this number (for example PFS 1532s) designates a stamp seal as opposed to a cylinder seal. The symbol * following this number designates an inscribed seal.
}

${ }^{14}$ Garrison and Root, Seals on the Persepolis Fortification Tablets (n. 3, above), 1. In addition, Garrison and Root have identified sixty analytically illegible but clearly discrete seals in their corpus.

${ }^{15}$ M. B. Garrison, 'Achaemenid iconography as evidenced by glyptic art: Subject matter, social function, audience, and diffusion', in Images as media: sources for the cultural history of the Near East and eastern Mediterranean (1st Millennium BCE), Orbis Biblicus et Orientalis 175, ed. C. Uehlinger (Freiburg 2000) 115-163 (125).

${ }^{16}$ Root, 'The legible image' (n. 6, above) 107. Here I have taken the most basic approach to connections; each seal equals one individual (even if the same name occurs on multiple seals). A more nuanced approach, trying to equate 
tracking the occurrence of specific seals can provide proxy data for tracking the activities of those individuals who owned and used these objects. Importantly, most of the seal-using individuals named in the archive are not part of Darius' inner circle. They are, instead, part of the group of non-elites my study is interested in. Using these seals, then, we can connect non-elites to specific images. Because these seals represent a great diversity of images and motifs, a floruit of artistic creativity that draws from a variety of cultural expressions and image-production traditions, we can understand something of the choices made by the nonelites who used them. ${ }^{17}$ These seals were applied to the tablets in social and economic contexts involving numerous human entanglements and imply a series of social actions that took place within a network of activities. These links between imagery, action, text, and individual (elite and non-elite) preserved in the Fortification archive, are what make a multifaceted social network analysis of it possible and fruitful.

\section{Social network analysis}

Developing in the middle of the twentieth century from the fields of sociometry, organizational anthropology, and graph theory, social network analysis is a methodology for the empirical study of relationships across space and time. Network analysis (of which social network analysis is one subfield) is not a predictive social theory; it is rather a loose federation of approaches that serves as a broad strategy for investigating social structures. ${ }^{18}$ The basic assumption behind social network analysis is that relationships between individuals shape their actions. Various analytical tools help to understand, describe in precise terms, and measure these relationships. ${ }^{19}$ Networks can be interrogated in multiple ways to answer many questions. The point is not merely to demonstrate that social networks exist, but, granting that they do, to examine the shifting, overlapping complexities that emerge from mapping them. ${ }^{20}$

At its most basic, a network is a set of nodes that are connected by ties (or edges). Edges can either be directed (with clear directionality of action) or undirected (lacking clear directionality). Further information about nodes and edges can be added in the form of variables and weights. As my case study will demonstrate below, a significant part of a network analysis involves translating empirical data into a set of tables that network visualization and analysis software can read. Here, the open source software Gephi is the method of choice. ${ }^{21}$

multiple seals to individuals, is one possible avenue for future work — as is a prosopographical approach leaning more heavily on the individual names when no seal or only a single seal is present.

${ }^{17}$ Root, 'The legible image' (n. 6, above) 94. See also M. C. Root 'Cultural pluralisms on the Persepolis Fortification Tablets', in TOPOI Suppl. 1. Recherches récentes sur l'empire achéménide (Lyon 1997) 229-252.

${ }^{18}$ M. Emirbayer and J. Goodwin, 'Network analysis, culture, and the problem of agency', American Journal of Sociology 99 (1994) 1411-54; R. Burt, 'Models of network structure', Annual Review of Sociology 6 (1980) 79-141.

${ }^{19}$ For some of the problems in the application of social network analysis to archaeological datasets see T. Brughmans, 'Thinking through networks: a review of formal network methods in archaeology', Journal of Archaeological Method and Theory 4 (2013) 623-62.

${ }^{20}$ C. Lemercier, 'Formal network methods in history: why and how?', in Social Networks, Political Institutions, and Rural Societies, Rural History in Europe 11, ed. G. Fertig (Turnhout 2015) 281-304 (286).

${ }^{21}$ M. Bastian, S. Heymann, and M. Jacomy, 'Gephi: an open source software for exploring and manipulating networks', International AAAI Conference on Weblogs and Social Media (2009). 
Social network analysis has experienced rising popularity over the last two decades in historical and archaeological inquiries centring on the ancient Mediterranean and Near East. Historical Network Research, a website dedicated to the use of network approaches within historical disciplines, lists eighty articles that apply network theory in some manner to ancient historical or archaeological questions. ${ }^{22}$ These range from broad syntheses to theoretical discussions and specific case studies detailing a variety of periods and topics. My own project builds on and expands the reach of these previous efforts in three significant ways:

1. Network approaches have seldom been applied to the Achaemenid Empire and have been underutilized to date in published studies of the Persepolis Fortification archive. $^{23}$

2. The Persepolis Fortification archive provides layers of information in a single ancient data set that permits exploration of non-elites to a remarkable degree of resolution.

3. Data from the archive (incorporating visual evidence of individual seal choices, dated informative texts eliciting information on people's interactions with other individuals at specific moments and engaged in specific activities) invites a marriage of the analytical strengths of social network analysis with more humanistic and traditional methods of archaeological, art historical, and historical study.

\section{Methods of social network analysis}

As a subfield of graph theory, social network analysis comes with its own set of analytical tools (algorithms) and vocabulary (an example can already be seen in the terms 'nodes' and 'edges'). Social network analysis typically follows a series of steps. First, one tries to represent the structure of a complete network in order to visualize the effect a given structure has on its individual actors. ${ }^{24}$ Once this initial step is taken, there are two different choices: whole network analysis or egocentric (ego) network analysis. ${ }^{25}$ Whole network, as its name implies, uses the entire network as an analytical frame while an ego network focuses on the ties a single individual possesses and uses. ${ }^{26}$ In what follows, I am using both approaches.

Different network structures can have significant influences on the speed at which information (be it goods, ideas, etc.) moves through a given network. Highly dense, overconnected networks can restrict the movement of information due to the numerous steps

\footnotetext{
${ }^{22}$ M. Düring, Historical Network Research at: http://historicalnetworkresearch.org.

${ }^{23}$ H. P. Colburn, 'Connectivity and communication in the Achaemenid empire', Journal of the Economic and Social History of the Orient 56 (2013) 29-52. A small circle of specialist scholars working directly on the tablets is certainly invested in the potentials of this type of analysis; but to date, the data are being used for internal purposes of coordinating intersections of data across the archive. Margaret Cool Root is spearheading a long-term collaborative digital humanities project on social networks in the empire via the Persepolis tablets.

${ }^{24}$ S. Wasserman and K. Faust, Social network analysis: methods and applications (Cambridge 1994) 4.

${ }^{25}$ C. Waerzeggers, 'Social network analysis of cuneiform archives: a new approach', in Proceedings of the second START conference in Vienne (17-19th July 2008), ed. H. D. Baker and M. Jursa (Oxford 2014) 208; R. A. Hanneman and M. Riddle, Introduction to social network methods (Riverside 2005) 8-9.
}

${ }^{26}$ C. Wetherell, 'Historical social network analysis', International review of social history 43 (1998) 125-144 (127). 
information must take to move through the system. ${ }^{27}$ So-called 'random networks', with low average path lengths but lacking hubs of nodes, also prove inefficient because they lack sustained structure in the form of cliques. 'Clique' is a social network analysis term for inward-facing subsections of a network that have a high number of ties within the subsection but few outside it. These cliques facilitate the efficient transfer of information. ${ }^{28}$ 'Small world' networks are those with moderate to large diameters, short average path lengths, and cliques. All small world networks share two properties: the so-called 'small world effect' (a low average path length, a property shared with random networks) and 'clustering' (demonstrating the presence of cliques). ${ }^{29}$ These small world networks have been found to be the most conducive to the efficient transfer of information. ${ }^{30}$ In order to determine if a network is dense, random, or small world in nature, different algorithms can quantify aspects of the network that can, in turn, help to understand the structure.

While the analyses that network software can apply are myriad, I will only touch on the few that I used in this study: diameter, average path length, and centrality. A network's diameter refers to the maximum number of connections required to traverse a given graph (that is, how many steps it takes for the two most distant nodes in the network to reach one another). Diameter can help us to understand the complexity of a network: a greater diameter generally means a more complex network. ${ }^{31}$ Average path length, taking into account the connectedness of all nodes in the network, can also provide insight into the general network structure. If a network's average path length is significantly above the diameter, communication within the network may be inefficient, if significantly below, information can flow easily. ${ }^{32}$ Networks with large diameters but small average path lengths facilitate the efficient movement of information and can be suggestive of a small world.

Centrality statistics provide a means of comparing the role or importance of various nodes within a single network. While numerous centrality measures exist, in this project I use two that measure centrality in different ways: betweenness centrality and eigenvector centrality. Betweenness centrality measures how important an individual node is for other nodes as these other nodes traverse the network. Specifically, it measures how often a specific node lies on the shortest path between two other nodes. ${ }^{33}$ Nodes with higher betweenness centrality scores are used more frequently for quickly traversing the network. Eigenvector centrality quantifies the importance of connections by measuring which individual nodes

${ }^{27}$ T. W. Valente, Network models and the diffusion of information (New Haven 1995); D. J. Watts, 'A simple model of global cascades on random networks', Proceedings of the national academy of sciences 99 (2002) 5766-71; R. Cowan, 'Network models of innovation and knowledge diffusion', in Clusters, networks, and innovation, ed. S. Breschi and F. Malebra (Oxford 2006) 29-53.

${ }^{28}$ D. J. Watts and S. H. Strogatz, 'Collective dynamics of "small-world” networks', Nature 393 (6684) (1998) $440-442$.

${ }^{29}$ F. Zaidi, 'Small world networks and clustered small world networks with random connectivity', Social network analysis and mining 3.1 (2013) 52. The presence of cliques can also be tested using clustering coefficients.

${ }^{30} \mathrm{~K}$. Larson, 'A network approach to Hellenistic sculptural production', Journal of Mediterranean Archaeology $26(2013) 237$

${ }^{31}$ K. Cherven, Mastering Gephi Network Visualization (Birmingham and Mumbai 2015) 182-183. There is some subjectivity in this measurement; a highly complex small network can have the same diameter as a non-complex large network. Other analysis can help qualify the diameter measurement.

${ }^{32}$ U. Brandes, 'A faster algorithm for betweenness centrality', in Journal of mathematical sociology 25 (2001) $163-177$.

${ }^{33}$ Cherven Mastering Gephi (n. 31, above) 195. 
have a high proportion of connections to other influential nodes. ${ }^{34}$ Eigenvector centrality is measured on a 0 to 1 continuum (values near 1 have higher influence while those near 0 have lower influence). ${ }^{35}$ If a network has a large diameter, low average path length score, and certain nodes with high centrality measures, it illustrates a small world.

This is only a small sample of possible network analyses designed to illustrate the potential (and in some cases potential pitfalls) in the application of social network analysis to the Persepolis Fortification archive material. Future research will incorporate a broader spectrum of analyses. While all of these measures feature some element of subjectivity and are only testing for a specific type of connection while ignoring others, they still provide powerful analytical tools for interpreting diverse realms of Achaemenid Persian social, economic, and political structure, as well as visual culture, as reflected in the Persepolis Fortification archive.

\section{Turning the Persepolis Fortification archive into a social network}

I proceed now to outline my methodology. Each seal in the PF archive, and by proxy the individual who used it, represented a node in my network. If two seals appeared on a tablet together, the tablet served as an edge that linked them. The seal of Dakizidda the camel driver served as my starting point. I operationalized this methodology as follows: Dakizidda's seal PFS 1532s only appears on one tablet in the PF corpus, PF 1711. Seal PFS 21, belonging to the 'supplier' named Karma (whom we have already met on PF 1787), also appears on this tablet. My first nodes, then, were PFS 1532s and PFS 21, and they were linked by an edge that represents the disbursement of goods recorded on PF 1711. Moving outwards, PFS 21 was far more common than PFS 1532s, appearing on eighteen tablets and co-occurring with sixteen different seals. Repeating this process and using Garrison and Root's Concordance of Seals to Tablets, vols I-III inclusive and Concordance of Tablets to Seals, vols I-III inclusive, I was able to enter a series of connections into a database, building out from PFS 1532 s to eventually encompass 202 nodes and 218 edges and ending when no more connections were available. In addition, I recorded a broad range of variables for each seal and tablet (goods exchanged, names of individuals, authorizing figure, location, date, etc.). This database, in the form of an edge table (recording source and target nodes) and a node table (recording node IDs and various attributes), was imported into Gephi and the software produced the visualizations seen in Figure 2. I call this network the 'network of seals and seal-using individuals connected to PFS 1532s'.

Since I am interested in non-elites operating in the Persepolis administrative region, I expanded the data to create two additional, alternative networks that included individuals beyond those whose seals were present in the network built around PFS 1532s. These two networks aim to recreate some of the interactions stated as taking place in the texts of the archive, but not preserved in the form of physical tablets. The PF texts that record rations for travellers (Hallock's 'Q Texts') sometimes identify individuals who provided travellers with a sealed document or who authorized the transactions (as in the example from PF 1787 above). ${ }^{36}$ Typically these individuals are elite and operate in the upper levels of the

\footnotetext{
${ }^{34}$ To use the popular social media platform Facebook as an analogy, the person who has the most friends who also have a lot of friends will have the higher Eigenvector centrality score.

${ }^{35}$ Cherven, Mastering Gephi (n. 31, above) 195.

${ }^{36}$ For Q Texts as a category, see Hallock, Persepolis Fortification Tablets (n. 3, above) 40-45.
} 
Figure 2: Two network visualizations of my network of seals and seal-using individuals connected to PFS $1532 \mathrm{~s}$, which demonstrate different methods of measuring centrality (betweeness centrality and Eigenvector centrality, see p. 8).
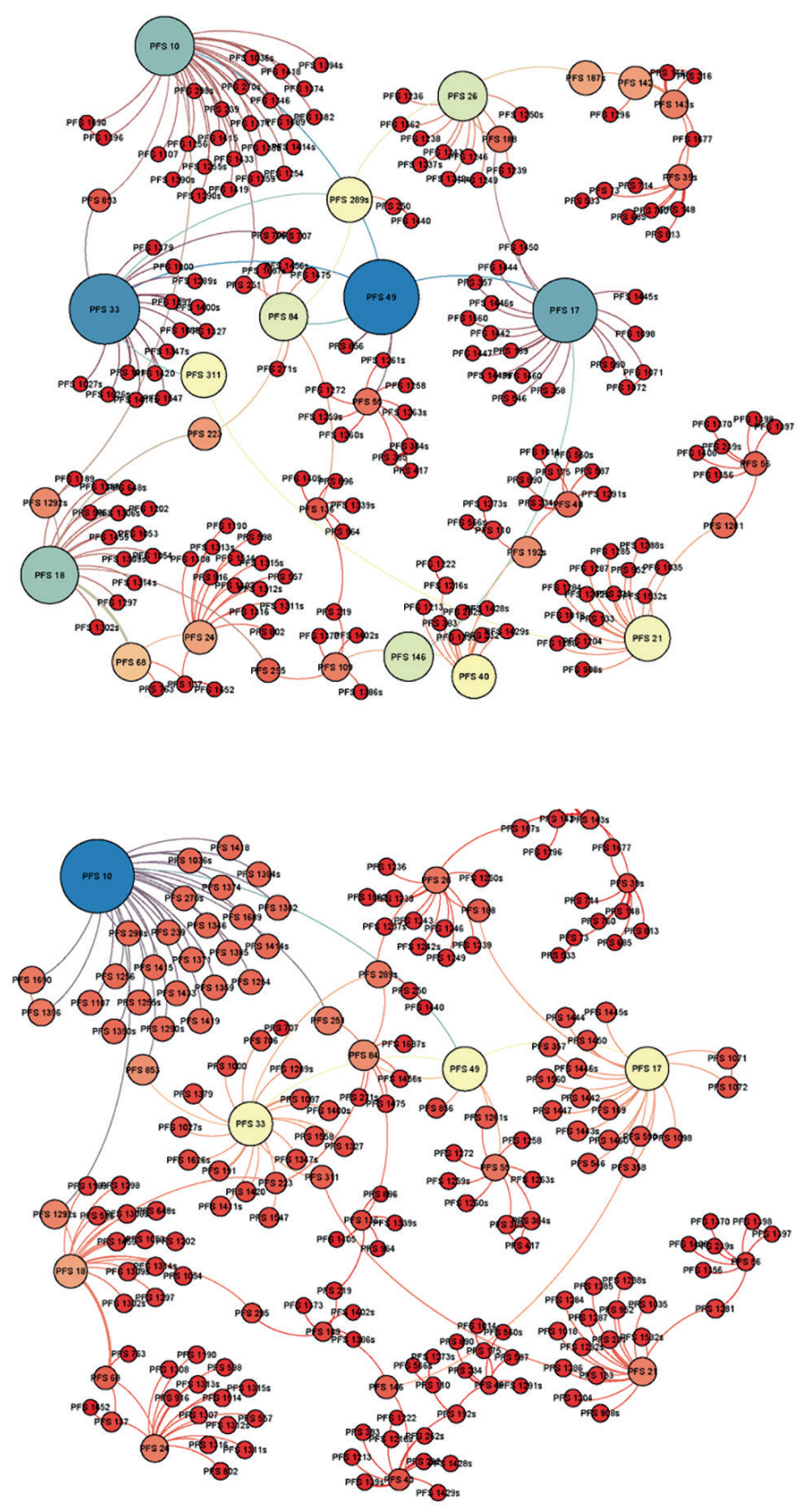

Figure 2a: In this network, betweenness centrality scores are represented by the size and colour of the nodes. The larger and bluer nodes have higher betweenness centrality scores (used frequently to quickly traverse the network), the redder and smaller nodes have lower betweenness centrality scores (used less frequently to traverse the network).

Figure 2b: In this network, Eigenvector centrality scores are represented by the size and colour of the nodes. The larger and bluer nodes have higher eigenvector centrality scores (high proportion of connections to other influential nodes), the redder and smaller nodes have lower eigenvector centrality scores (low proportion of connections to other influential nodes). 
Figure 3: Two network visualizations of my network of seals and seal-using individuals connected to PFS 1532s with 'authorizing' figures, which demonstrate different methods of measuring centrality (betweeness centrality and Eigenvector centrality, see p. 8).

Figure 3a: In this network, represented by the size and colour of the nodes. The larger and bluer nodes have higher betweenness centrality scores (used frequently to quickly traverse the network), the redder and smaller nodes have lower betweenness centrality scores (used less frequently to traverse the network). betweenness centrality scores are

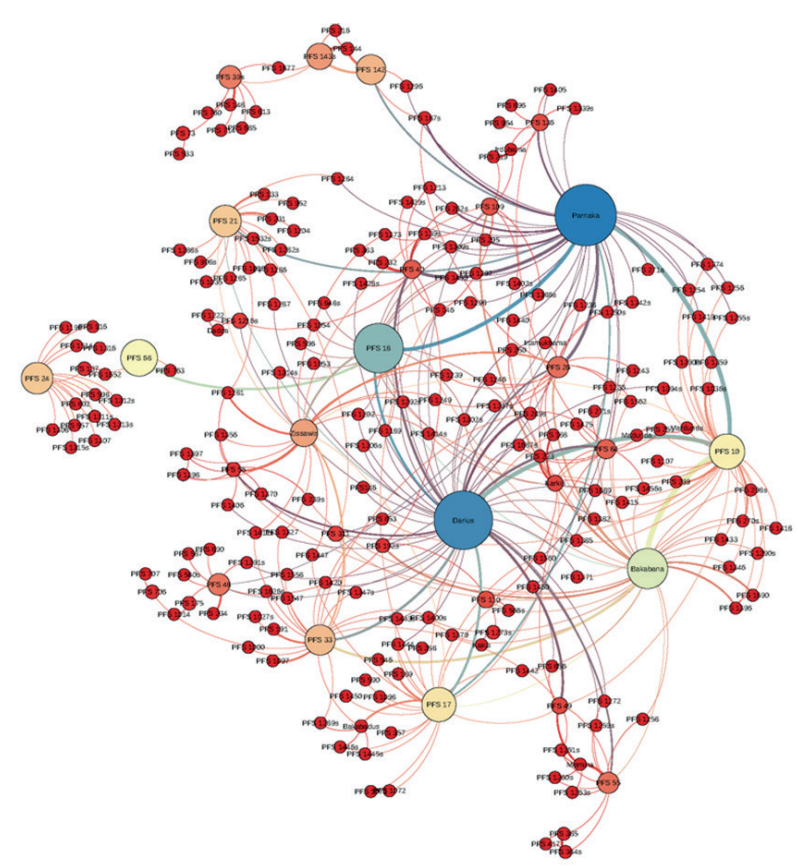

Figure 3b: In this network, Eigenvector centrality scores are represented by the size and colour of the nodes. The larger and bluer nodes have higher eigenvector centrality scores (high proportion of connections to other influential nodes), the redder and smaller nodes have lower eigenvector centrality scores (low proportion of connections to other influential nodes). The thicker edges in this visualization show weights, meaning repeated connections between a series of seal-using individuals and authorizing figures.

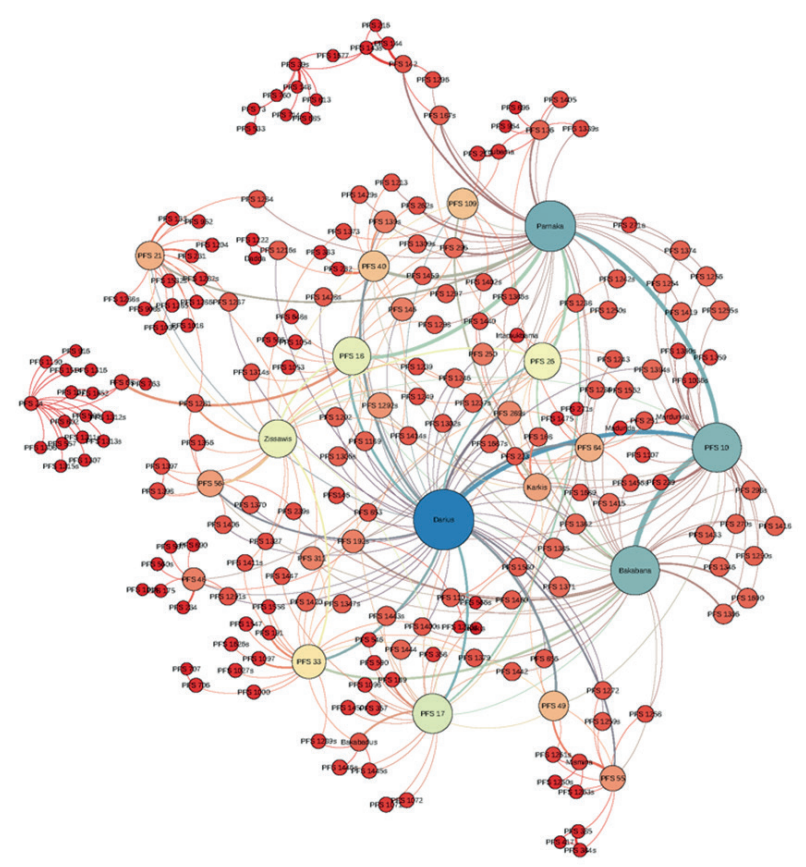


Persepolis administration (including Darius himself). Many of these 'authorizing' figures have personal seals that appear in the PF corpus; one example is Parnaka who successively uses two personal seals, PFS 9* and PFS $16 * .{ }^{37}$ In the network built off Dakizidda, however, all of these elite individuals appear only when 'authorizing' a transaction or providing a 'sealed document'. None of these 'authorizing' or 'sealed' documents (which would have been on parchment or papyrus) survive; but they imply another layer of administrative practices and an additional network of connections. The network with authorizing figures thus provides a different look at Persepolis' social structure, with a clearer picture of Darius' court and other elites (I call this network the 'Network of seals and seal-using individuals connected to PFS 1532s with “authorizing" figures': Figure 3).

The PF tablets often also record the various individuals (both human and animal) to whom the receiving individuals will distribute the goods they acquire (i.e. the thirtythree camels of Bawukšamira). Most of these goods are distributed to various groups of people (groups translated by Hallock as being made up of men, women, gentlemen, servants, sometimes with ethnic attributions, such as Skudrian workmen). Since I added the 'authorizing' individuals to include the Persepolis elite in my network, these recipients were added in a separate network visualization in order to get at the opposite, lowest end of the social spectrum, the unnamed masses that provided much of the labour and consumed most of the goods moving about in the Persepolis region. Although I have not included a visualization of this network here due to its size and congested nature, I believe this larger network offers the most holistic way forward for populating Achaemenid Persepolis and can be a powerful tool for understanding more about a range of individuals from numerous positions in the Achaemenid social hierarchy.

\section{Whole network analysis}

7a. Network of seals and seal-using individuals connected to PFS 1532s

Taking into account the various network analytics in play (diameter, average path length, betweenness, and eigenvector centrality), this network appears to be a mirror of a small world network in numerous aspects while not necessarily completely fulfilling the various small world criteria. The diameter of the network is 11 and the average path value is 3.947. The average path value being much lower than the diameter suggests that information of whatever kind would move through the network quite efficiently. Looking at the betweenness and eigenvector centrality scores, the same five seals (PFS 10, PFS 17, PFS 18, PFS 33, and PFS 49) have the highest scores in both centrality measures. ${ }^{38}$ As is illustrated in the visualization of this network (Figure 2), these seals control cliques of other seals. Put together, this suggests a type of small world network that would promote efficient movement of information throughout the system. The number of nodes and edges however slightly problematizes a small world hypothesis for a network built around only Dakizidda and his fellow seal-using individuals. With only 218 edges connecting 202 nodes, this network is

\footnotetext{
${ }^{37}$ Hierarchical protocols seem to have dictated that neither of Parnaka's seals ever appeared on a tablet also sealed by another individual. See Garrison and Root, Seals on the Persepolis Fortification Tablets Volume I (n. 3, above) 404-406 for (PFS 9*) and 92-24 for (PFS 16*).

${ }^{38}$ The scores for eigenvector and betweenness centrality (rounded to the nearest hundredth) respectively are: PFS 10, 6,017.01 and 1; PFS 17, 6689.73 and 0.49; PFS 18, 5,777.27 and 0.32; PFS 33, 7488.67 and 0.50; and PFS $49,8158.3$ and 0.51 .
} 
relatively shallow with few overlaps and interconnections. This network structure does not necessarily mirror what one might expect from a network in the 'real world'; this network is missing connections. ${ }^{39}$ The network of seals and seal-using individuals connected to PFS $1532 \mathrm{~s}$ with 'authorizing' figures, representing another level of administrative connections present at Darius' Persepolis, acts as a more accurate representation of the small world network at Persepolis.

7b. Network of seals and seal-using individuals connected to PFS 1532s with authorizing figures

The network that includes seal-using individuals and 'authorizing' figures connected to PFS $1532 \mathrm{~s}$ has a few more components than the network of only seals and seal-using individuals, containing 217 nodes and 384 edges (Figure 3). The diameter, at 10, and the average path length, at 3.575, are smaller than the network of seals and seal-using individuals. By taking into account this added level of administration at Persepolis (and the offices of assistants that must have aided the elite administrators in their activities), the number of edges is more in line with a 'real world' network and the small-world structure is even more evident. The centrality scores corroborate this picture (showing evidence for cliques).

What does the presence of a small world network in the PF archive mean? First, it highlights the highly effective bureaucratic apparatus at Persepolis. This feature makes intuitive sense, but here is analytical evidence for the efficiency of the Persepolis administration, crucial for operating an empire of this size. While the efficient and welldocumented flow of goods is the obvious pragmatic goal of an imperial disbursement network such as this, the small-world network structure also points to something equally important: a mechanism of the diffusion of non-material culture (ideas, trends, political control) that may highlight how the Achaemenid system of hegemonic management worked over such a large geographic extent. Based on the evidence that similar networks were present (and linked to one another) at numerous if not all important Achaemenid centres, perhaps Dakizidda's network illustrates an underlying factor that promoted the success of the Achaemenid imperial project.

The centrality scores present in these network visualizations also highlight certain aspects of the social structure at Persepolis. Certain administrators and members of Darius' court had high eigenvector and betweenness centrality scores: (unsurprisingly) Darius himself, Parnaka (likely Darius' uncle and the chief administrator at Persepolis from 506497? BCE), Ziššawiš (Parnaka's successor) ${ }^{40}$ and Bakabana. ${ }^{41}$ The importance of these individuals fits nicely within other studies of the social structures of Darius' Persepolis. The top tier of the Persian society consisted of Darius and his family (including Parnaka and probably Ziššawiš), followed by members of a select group of Persian noble families. ${ }^{42}$ Ties, by either blood or marriage, to the king were the primary means of joining this superelite. Garrison has suggested that beneath these individuals in the social hierarchy were

\footnotetext{
${ }^{39}$ For a more realistic picture of nodes and edge counts for 'real world' and 'small world' networks see Zaidi 'Small world networks' (n. 29, above).

${ }^{40}$ Briant, From Cyrus to Alexander (n. 2, above) 435.

${ }^{41}$ The scores for eigenvector and betweenness centrality (rounded to the nearest hundredth) respectively are: Darius, 6481.18 and 1; Parnaka, 6871.20 and 0.80; Ziššawiš, 2106.42 and 0.51; and Bakabana, 3918.34 and 0.76.

${ }^{42}$ Briant, From Cyrus to Alexander (n. 2, above) 331-338.
} 
the Iranian administrative elite (perhaps including some of the other authorizing figures), people whose loyalty Darius needed to run his empire. ${ }^{43}$ What the evidence from this network can highlight (in a different manner from these earlier studies) is a third, diverse group of individuals, separate from these two elite groups. This variable group contains those individuals I would categorize as non-elite (they are not from Darius' family, the Persian nobility, or innermost administrative elite). These non-elites were also active, crucial participants at Darius' Persepolis and in the networks of the archive.

The importance of these non-elites can best be seen in a set of seals, PFS 10, PFS 17, PFS 18, PFS 21, PFS 24, PFS 26, PFS 33, PFS 68, and PFS 142. All these seals (and the individuals who used them in the transactions) have either betweenness or eigenvector centrality scores higher than various authorizing figures (Figure 3). ${ }^{44}$ PFS 10, PFS 24, PFS 68, and PFS 142 were office seals: that is, they are used by individuals who are usually but not always named in the transactions, but not as their personal property. ${ }^{45}$ The other seals (PFS 17, PFS 18, PFS 21, PFS 26, and PFS 33) belong to specific named individuals. ${ }^{46}$ These individuals appear in a second tier of connections right below Darius and Parnaka and on a par with Bakabana and Ziššawiš. Ušaya a wine seller (PFS 17), Mirayauda a grain supplier (PFS 18), Karma a flour supplier (PFS 21), Barušiyatiš a grain supplier (PFS 26), and an unnamed supplier (PFS 33) all serve as crucial nodes in this network. The people who possessed these seals were operating mostly as intermediaries, facilitating the movement of goods between a central supplier and various satellite groups. The individuals in these satellite groups, located on the periphery of the network, then consumed the flour, grain, and wine. I would suggest that these seal-using individuals were non-elite 'career operatives' at the heart of the imperial system. They facilitated movement across the imperial landscape and the activities of both the 'haves' and the 'havenots'. The actions these operatives organized and kept running generated and maintained the economic structure that sustained the Achaemenid institutions of governance, social life, and communication. The economic activities these career operatives undertook also influenced the flowering of seal production in the Persepolis milieu that we can glimpse through the archive itself; this demonstrates the spillover effect of this type of economic activity, yielding demand for artistic innovation. ${ }^{47}$

${ }^{43}$ Garrison has studied the occurrences of the royalname seals inscribed with Darius, as used on the Fortification tablets, concluding that this very particular small class of seals constitutes royally gifted seals used as a means of solidifying the loyalties of a social group slightly beneath the royal and elite noble core. M. Garrison, 'The royal name seals of Darius I', in Extraction and control. Studies in honor of Matthew W. Stolper, Studies in Ancient Oriental Civilization 68, ed. M. Kozuh, W. Henkelman, C.E. Jones, and C. Woods (Chicago 2014) 67-104, esp. 88-89.

${ }^{44}$ The scores for betweenness and eigenvector centrality (rounded to the nearest hundredth) respectively are: PFS 10, 3233.68 and 0.77; PFS 17, 3083.37 and 0.57; PFS 18, 5200.43 and 0.54; PFS 21, 2716.60 and 0.34; PFS 24. 2717 and 0.44 ; PFS 26, 1249.41 and 0.51; PFS 33, 2529.77 and 0.45; PFS 68, 3399 and .068; and PFS 142, 2448.5 and 0.11 .

${ }^{45}$ For example, PFS 142 was used once in Darius' twenty-second regnal year by one Minduka but in the twentythird Pirratamka used this seal six times.

${ }^{46}$ For PFS 10 see Garrison and Root, Seals on the Persepolis Fortification Tablets Volume I (n. 3, above) 361-362. Hallock associates this seal with flour supply at Kurdušum. For PFS 24, see Garrison and Root, Seals on the Persepolis Fortification Tablets Volume I (n. 3, above) 421-422. While the supplier Mirayauda uses this seal extensively, the authors suggest it is likely actually associated with an office of supply at Umpuranuš. I have identified PFS 68 as an office seal based on the various names associated with it in the PF archive texts.

${ }^{47}$ See H. P. Colburn, 'Seal production and the city of Persepolis', in The Art of Empire in Achaemenid Persia: Festschrift in Honor of Margaret Cool Root, ed. E.R.M. Dusinberre and M.B. Garrison (Leiden in press). 
There is a complex sliding scale of status present in these data from the PF archive and social network analysis can help visualize and quantify these relationships. A more detailed analysis of one such individual within this variable class (a network biography in a sense) can illustrate more aspects of life as a transitional non-elite. I move now to my case study of Dakizidda the camel driver. I present him as an excellent and interesting representative of the transitional non-elite category and I proceed to demonstrate through social network analysis how his life reveals itself to us in its complexities of experiential interaction.

\section{Dakizidda: case study of a camel driver}

Dakizidda the camel driver appears on only one tablet in the PF archive, PF 1711, where his seal PFS 1532s is applied. Hallock's translation of this tablet reads:

Ninety (BAR of) flour, supplied by Karma, Dakizidda the camel driver received. He gave (it as) rations to ten camels. Twelfth (Elamite) month, twenty-second year. ${ }^{48}$

The rationales for focusing on Dakizidda for this pilot project are several. First, his limited occurrence presents at once a workable case study for this exploratory inquiry and also de facto presents a glimpse of an individual who is just passing through the region and yet who in this single attested encounter can be seen caught up in a web of associations. Second, the nature of his profession is at once appealing on a human level - evocative of the romantic imagery associated with camels crossing desert landscapes over a vast imperial domain and emblematic of the significance of camels economically, militarily, and symbolically (as well as the human work their maintenance necessitated). Third, Dakizidda's seal is full of intrigue in its own right, as we shall see.

Let us take a look at Dakizidda's profession as a camel driver. ${ }^{49}$ While no systematic studies of camels or camel drivers in the Achaemenid Empire exist, these animals served numerous functions. Classical testimonia as well as ancient Near Eastern sources make it clear that camels functioned as pack animals for crossing inhospitable terrain, as military mounts, and as sources of food..$^{50}$ These uses are borne out by documentation of later times

\footnotetext{
${ }^{48}$ Hallock, Persepolis Fortification Tablets (n. 3, above), 469. The twenty-second year of Darius is 500 BCE.

49 The full sense of the Elamite term, translated by Hallock as 'camel driver', is not entirely clear. Hallock acknowledges the difficulties in rendering many such terms in his translations when it comes to occupational titles (Hallock, Persepolis Fortification Tablets (n. 3, above), 42). He does not directly address translation issues with the term driver as a qualifier of camels. He does, however, state that on some tablets, the Elamite word he renders as 'horsemen' refers not to those who ride horses, but to the people who take care of them (Hallock, Persepolis Fortification Tablets (n. 3, above) 40. It is not certain that this distinction works for camels as well. Hallock's choice of 'driver' definitely implies a specific active role in moving groups of these animals across the landscape rather than simply riding one and Dakizidda's management of ten camels in the text obviously was a circumstantial factor in Hallock's thinking. The problem Hallock and others continue to face involves the paucity of other Achaemenid Elamite texts with such a vast range of quotidian vocabulary (as opposed to royal rhetoric). Hallock's 'licence' and his thoughtful ambiguity on certain points is borne from necessity.

${ }^{50}$ For an overview of camels in the neo-Assyrian period see A. Kuhrt, 'The exploitation of the camel in the NeoAssyrian Empire', in Studies on Ancient Egypt in honour of H.S. Smith, Egypt Exploration Society occasional papers 13, ed. A. Leahy and J. Tait (1999) 179-184. For the role of camels in warfare see Hdt. I.77.4 and I.10.5. For camels as food see Hdt. I.133; Ath, IV. 145. According to Strabo (XV.3.17), camel marrow, an apple, and nothing else, was eaten by the Persian bridegroom on his wedding day, with the implication that this diet would enhance sexual performance. See now also E. Filippone, 'Goat-skins, horses and camels: how did Darius' army cross the Tigris?', in Des contrées avestique à Mahbad, via Bisotun. Études offertes en hommage à Pierre Lecoq, Civilisations du Proche-Orient III. Religions et Culture 2, ed. C. Rédard (2016) 25-60, which reaches me too late for in-depth consideration.
} 

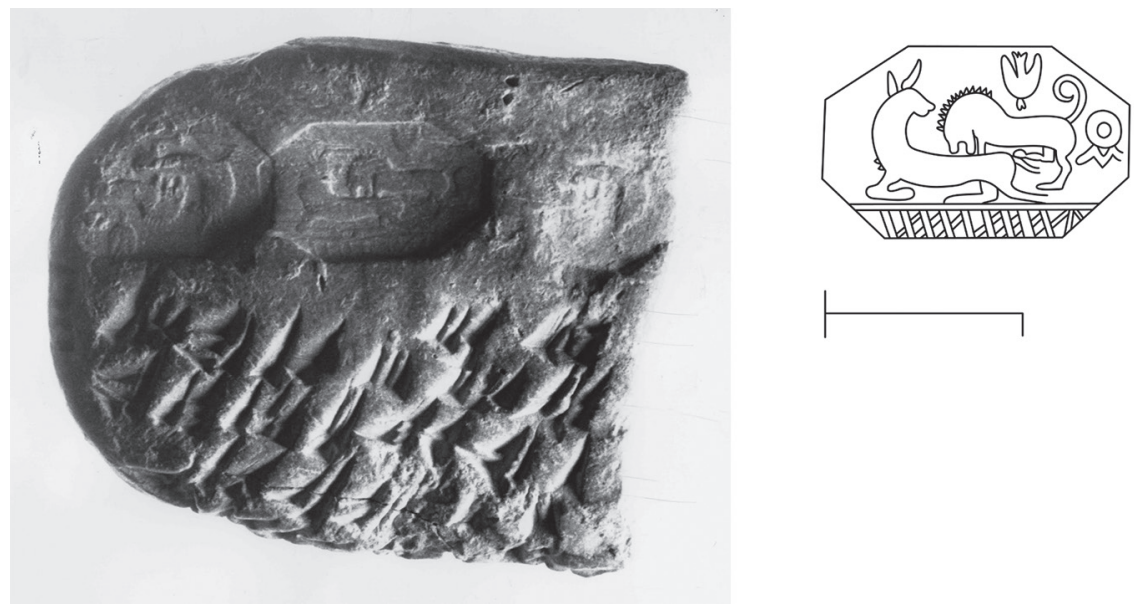

Figure 4a: A photograph of tablet PF 1711 RV, bearing three impressions of PFS 1532s.

Figure 4b: A composite line drawing of Dakizidda's seal PFS 1532s. Images courtesy of M.B. Garrison, M.C. Root, and the Persepolis Seal Project.

and from ethnographic observation. Both one-humped (Dromedary) and two-humped (Bactrian) camels were certainly used in the Achaemenid Empire. ${ }^{51}$ Dromedaries are prominent today, as in antiquity, in the west (where they excel in desert terrain), whereas Bactrian camels are and were in Achaemenid times particularly at home and useful in the east for challenging mountain terrain. In both cases, their size, strength, and ability to go long distances without water made them high-value beasts of burden and transport. On the Apadana reliefs of Darius on the Persepolis platform, one delegate group (the Arabians, group 20) brings a dromedary to the king as a gift. ${ }^{52}$ Four peoples of the empire bring the Bactrian camel to the king (a set of peoples from the eastern lands of the realm, traditionally numbered groups $7,13,15$, and 20). ${ }^{53}$ The appearance of the animals on the ceremonial Apadana reliefs emphasizes the importance and the prestige of these creatures to the empire. ${ }^{54}$ The Apadana reliefs also operate in another symbolic register. Due to the inhospitable terrain in the areas from which these delegates originate, the camels can be viewed as gifts that symbolically and literally unlock these various regions to the king and his administration. Interestingly, this prominence of camels on the Apadana reliefs is not replicated strongly in glyptic traditions around the empire, as far as evidence currently

\footnotetext{
51 '... there can be no doubt that north Arabia was crossed by camel caravans, not just between Arabia Felix and the Palestinian coastal ports (Gaza) that Herodotus calls emporia (III.5), but also between the Nile Delta and the Euphrates' (Briant, From Cyrus to Alexander (n. 2, above) 378).

${ }^{52}$ Group 20 is, by consensus, identified with the Arabian delegation: R. Hachman, 'Die Völkerschaften auf den Bildwerken von Persepolis', in Beiträge zur Kulturgeschichte Vorderasiens. Festschrift für Rainer Michael Boehmer, ed. R. Dittmann and H. Hauptmann (Mainz 1995) 223.

${ }^{53}$ Group 4: Identified as either the Aryans or Arachosians; Group 7: identified with either the Drangians or Arachosians/Aryans; Group 13: identified with the Bactrians or Parthians; and Group 15: identified with the Arachosians or Bactrians. See Hachman, ‘Die Völkerschaften' (n. 52, above) 223.

${ }^{54}$ R. Bulliet, The camel and the wheel (New York 1975) 157. The camels on the Apadana are very faithfully depicted, even down to the Dromedary's nose halter and the Bactrian's nose peg. The artists of the Apadana had no problem producing exceedingly accurate representations of these animals (M. C. Root, 'Animals in the art of ancient Iran', in A history of the animal world in the ancient Near East, ed. B. J. Collins (Leiden 2002) 169-209).
} 


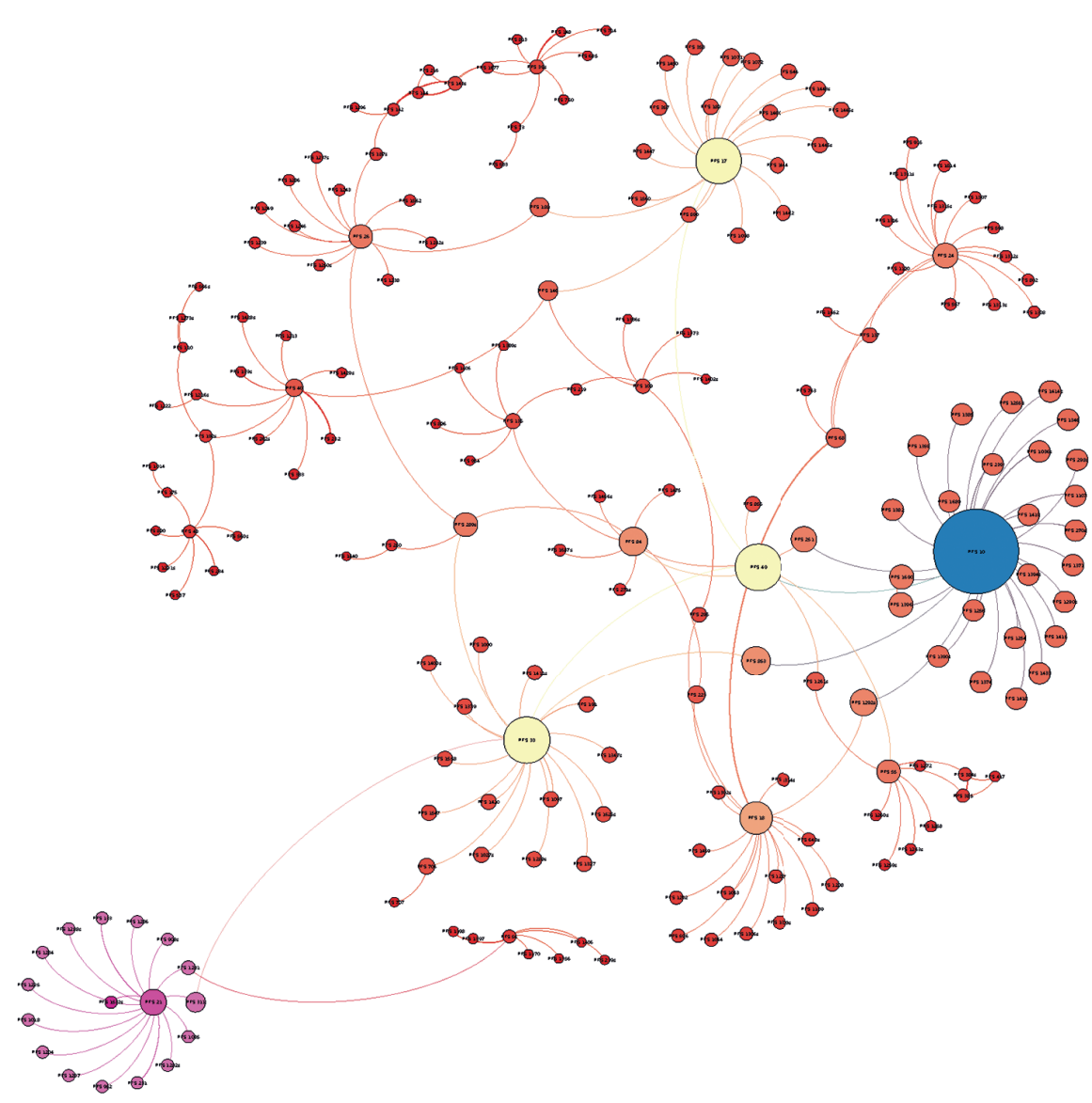

Figure 5: Network visualization of my network of seals and seal-using individuals connected to PFS $1532 \mathrm{~s}$ with Dakizidda's ego network, showing seals within two degrees of separation from PFS 1532s, identified in pink. Eigenvector centrality scores are represented by the size and colour of the nodes.

suggests. Not a single camel appears in the seals of the PF corpus, for instance. ${ }^{55}$ The camel, for whatever reasons, does not appear to have particularly inspired seal patrons to commission objects incorporating images of the beast. ${ }^{56}$

${ }^{55}$ Root, 'Animals in the art of ancient Iran' (n. 54, above) 203-204. Rather few Achaemenid era seals portray camels. Three stamp seals applied to Achaemenid period bullae from Daskyleion, imperial satrapal capital of Hellespontine Phrygia, depict Bactrian camels - two serving as galloping mounts: D. Kaptan, The Daskyleion Bullae: Seal Images from the Western Achaemenid Empire, Achaemenid History 12 (Leiden 2002) specifically DS 69,70 , and 102). The papyrus documents these bullae once sealed may have come to Daskyleion from a variety of imperial regions. The documents are not extant. I know of two unprovenanced cylinder seals that depict dromedary camels - both as mounted beasts: (Briant, Cyrus to Alexander (n. 2, above) 232, citing H. Frankfort Cylinder seals; a documentary essay on the art and religion of the ancient Near East (London 1939) Pl. XXXVI, m (De Clerc Collection); D. Collon, First impressions. Cylinder seals in the ancient Near East (London 2005) no. 740 which may be Neo-Babylonian rather than Achaemenid in date). A third unprovenanced cylinder (Collon no. 735) shows a pair of Dromedaries pulling the chariot of an elite personage.

${ }^{56}$ As Root notes (Root, 'Animals in the art of ancient Iran' (n. 54, above) 204), evidence from the Indo-Iranian 
While they are absent in seal images, in the area around Persepolis camels would have been key tools for crossing the vast salt deserts of central Iran. With this in mind, I would suggest we imagine these camel drivers as the 'long haul truckers' of the Achaemenid world, facilitating the movement of goods great distances and bearing responsibility for the health and sustenance of a valuable, even indispensable, mode of transport. ${ }^{57}$ Dakizidda and the other camel drivers working in and passing through Persepolis as we glimpse them on the PF tablets are important individuals with highly specialized skills, but they are not elite individuals.

In addition to his distinct profession, Dakizidda also owned a unique seal. This stamp seal (PFS 1532s) depicts a lion mounting a bull from the rear, similar (though not identical) in composition to the lion-bull images found on the Apadana stairs and ubiquitous on other sculptural facades of Persepolis (for the seal see Figure 4). Although numerous seals depict lions attacking bulls, this is the only seal from the Garrison and Root research corpus that depicts a lion-bull encounter with this particular compositional dynamic so close to that of the monumental relief - which relates to cosmic cycles. The seal imagery is carved in the local Fortification style. The pyramidal stamp seal form is at home in the Near East whence it influences stamp seal production in the western regions of the empire. The hatched exergue and the insignium in the upper field of the image resonate with a body of glyptic material associated with western Anatolia. ${ }^{58}$ The seal was applied three times on the reverse of PF 1711 in an interlocking chain with alternating orientations (see Figure 4). This creative seal application is extremely distinctive. It bespeaks an individual who was proud of his seal and who was given the time at the moment of this disbursement transaction to let his seal 'speak'. The moment of Dakizidda's intersection with the administrative system was one that gave him the scope for a human engagement around his seal as part of what Root has characterized as a 'social nexus' ${ }^{59}$ Root has suggested a possible meaning for the imagery of the PFS 1532s seal, relating the motif to the dual manifestations of light so critical to a person who traverses the land (the lion representing the sun and the bull signifying the moon). She has further suggested that the triple application Dakizidda creates evokes a passage of some kind, for example Dakizidda's camels moving in file across the landscape illuminated by the light of sun and moon. ${ }^{60}$ As will be discussed below, information from my social network analysis can further enrich this iconographic analysis. Instead of choosing a seal with clear topical links to his profession (such as the image of a camel), Dakizidda chose this particular image because of some meaning it held for him.

Thus, in addition to getting at this non-elite individual's economic and social activity

textual traditions of the Rig Veda and Avesta make the paucity of camel representations quite striking. In these texts, while the camel is lower in the hierarchy than a bull or cow-calf combination, they are still valued animals (see also Bulliet, The camel and the wheel (n. 54, above) 151-175). The camel's close association with nomads, potentially operating outside official Achaemenid control, could be one explanation for their noted artistic absence.

${ }^{57}$ See, for example, A. Azzoni and E. R. M. Dusinberre, 'Persepolis Fortification Aramaic tablet seal 0002 and the keeping of horses', in Studies in honor of Matthew W. Stolper, Studies in Ancient Oriental Civilization 68, ed. M. Kozuh, W. Henkelman, C. E. Jones, and C. Woods (Chicago 2014) 189-206, for a horse text from PFAT (Persepolis Fortification Aramaic Tablet) corpus. The care and feeding of large mammals would require special knowledge and a degree of trust (both camels and horses were important, expensive investments).

${ }^{58}$ Root, 'The legible image' (n. 6, above) 267-269; M. C. Root, 'Pyramidal stamp seals: the Persepolis connection', in Studies in Persian history: Essays in memory of David M. Lewis, Achaemenid History XI (Leiden 1998) 257289; Root, 'Cultural Pluralisms' (n. 17, above).

${ }^{59}$ Root, 'The legible image' (n. 6, above) esp. 109-111.

${ }^{60}$ Root, 'Animals in the art of ancient Iran' (n. 54, above) 203. 
through studying the tablets, we can also try to unravel the aesthetic and cultural choices he made through analysis of the glyptic evidence. Furthermore, by looking at the formal characteristics of the seal (noted above) we can expand upon our understanding of Dakizidda. ${ }^{61}$ His seal presents entangled local and extra-regional influences, very fitting for our Achaemenid 'trucker'. Although we have no way of proving the material his seal was made of from the ancient impressions, it was almost certainly made of a hard beautiful stone (such as chalcedony) as was typical for pyramidal stamp seals of the day. It would have had a metal fitting. In sum, PFS 1532s was a possession to be proud of and one that implies a patron's discretion. Social network analysis makes a set of similar entanglements, implicit in his seal, explicit by connecting him to various individuals and social groups. With this basic biography in mind, we can turn to the social network of individuals who influenced and interacted with our camel driver.
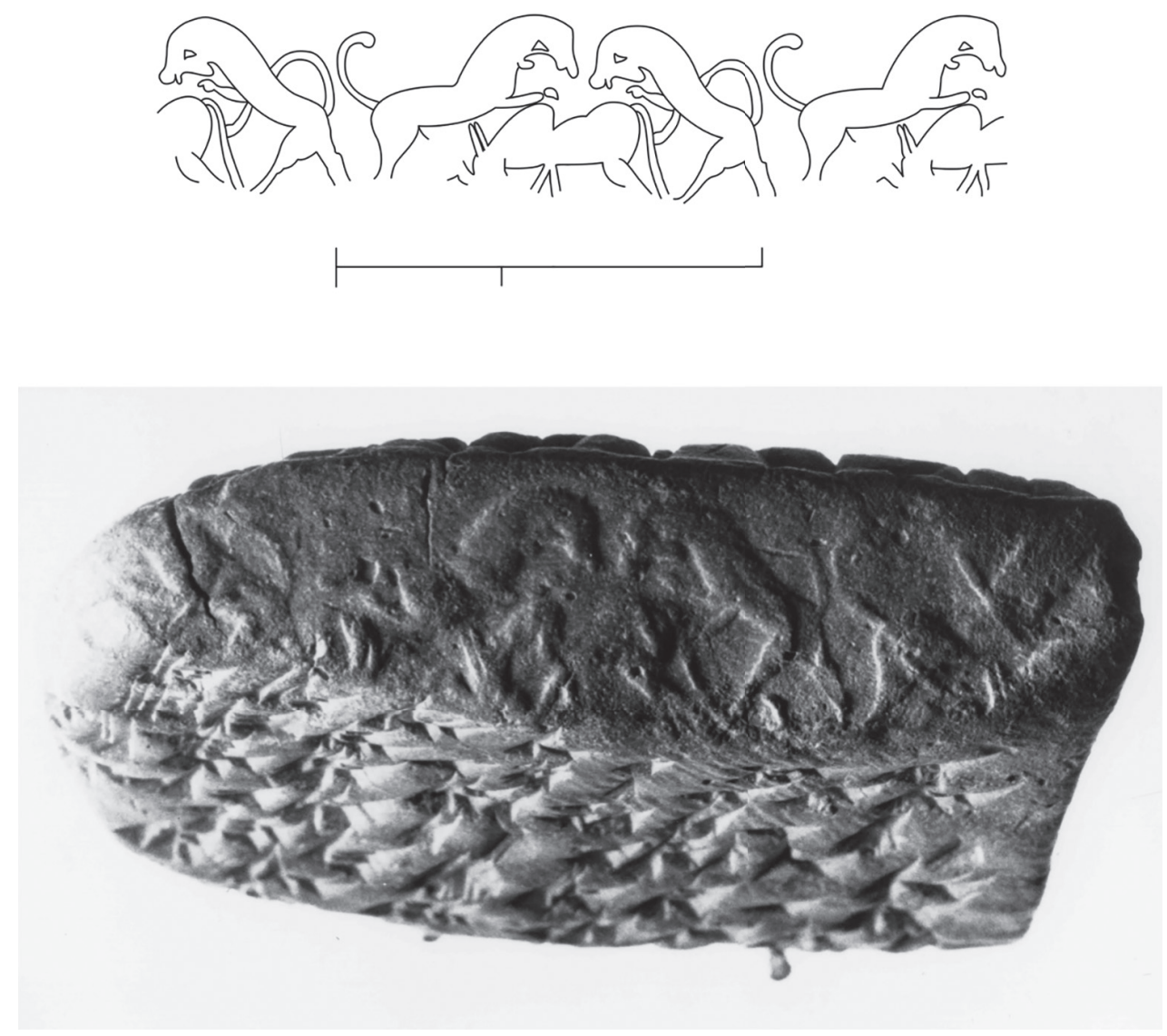

Figure 6a: A composite line drawing of Ukbakurna's seal PFS 1035. Images courtesy of M.B. Garrison, M.C. Root, and the Persepolis Seal Project.

Figure 6b: A photograph of tablet PF 1080 UE, bearing an impression of PFS 1035.

${ }^{61}$ The name Dakizidda's ethnic connotations deserve further study. 
To learn more about Dakizidda, I zoomed in on his ego network, rather than the larger network of seals connected to PFS 1532s. Dakizidda's ego network is an embedded network, one cluster within the broader whole. If the individuals in any given network only have local knowledge of those around them, an embedded ego network can illustrate those ties that have direct effects on the individual (see Figure 5). By focusing on a single person (Dakizidda) and his relationships, we can begin to explore different ways in which the social structure at Persepolis directly influenced a single individual.

For this ego approach, I looked only at those seals within two degrees of separation from Dakizidda's PFS 1532s: seventeen individual seals (PFS 1532s, PFS 21, PFS 908s, PFS 952, PFS 133, PFS 1018, PFS 1035, PFS 1204, PFS 1281, PFS 1282s, PFS 1284, PFS 1285, PFS 1286, PFS 1287, PFS 1288s, PFS 231, and PFS 311, and PFS 1532s) on eighteen different PF tablets. PFS 133 and PFS 231 both occurred on two separate tablets along with PFS 21. The transactions on all eighteen tablets took place in Darius' twentysecond regnal year (500 BCE). One transaction took place in the sixth Elamite month, five of the transactions took place in the first two months, seven took place in the ninth to the thirteenth months, and five lacked a more specific date than the twenty-second regnal year. Karma (owner of PFS 21) served as a central node in this network and supplied the various individuals mostly with flour (fifteen tablets), although Karma also occasionally supplied grain (two tablets) and wine (one tablet). The amount supplied varies considerably, running from 246 BAR to 7 QA (0.7 BAR). All of the goods exchanged in this small network appear to have been used for travel rations of some kind, although only four of the tablets denote specific paths of movement. This network, then, could represent a community of travellers and merchants who moved only at particular times of the year, supplied by Karma's goods, perhaps even in tandem with one another. The community aspect is important, for in their common tie to Karma they could have shared interactions that shaped a variety of choices.

Three of the individuals in this small network appear to have been involved in camel driving in some capacity: Dakizidda (PFS 1532s on PF 1711, see above) and Ukbakurna (PFS 1035 on PF 1080) are both described as camel drivers in the texts, while Bawukšamira (PFS 311 on PF 1786) uses the flour he received to provision thirty-three camels.

PF 1080: 277.5 BAR (of) flour, supplied by Karma, Ukbakurna the camel driver received. Twenty-seven gentlemen each received monthly 4.5 BAR. Fifteen servant boys each (for) one month received 3 BAR. First (Elamite) month. (For) a period of twenty days (in) the second (Elamite) month they received (travel) provisions, twenty-second year. Twenty-seven gentlemen each received 3 BAR. Fifteen servants each received 2 BAR.

PF 1786: 9.9 BAR (of flour?) Bawukšamira received, (for) rations of camels. Coming from Susa, he carried an authorization of Bakabana. He went to Persepolis. Thirty-three camels consumed 3 QA. Second (Elamite) month, twenty-second year.

Both Bawukšamira and Dakizidda's camels receive 0.3 BAR (3 QA) as their ration, suggesting this is a set amount provided for camels. This points towards a degree of standardization in the protocols and infrastructure needed to run a camel-driving operation. Dakizidda and Ukbakurna are, in fact, the only two camel drivers mentioned by name in the whole Hallock 1969 PF tablet corpus and the only two camel drivers with personal seals. ${ }^{62}$

${ }^{62}$ Hallock, Persepolis Fortification Tablets (n. 3, above) 313, 486. Camel drivers also appear on PF 1845 and PF 1950 but no individuals are named. PF 1845 only has a single seal, PFS 2, belonging to Irruppiya, a high ranking 
We can see in this ego network the types of people - fellow camel drivers and 'career operatives' - with whom Dakizidda was likely to collaborate, exchange ideas, and interact on a regular basis. We can begin to see the social circles in which people of Dakizidda's standing would have moved in Persepolis, a little window into how life would have worked for this important subset of the population moving around a vast domain. Dakizidda and his peers were successful enough to commission their own seals and it is with this glyptic evidence that I will conclude my study. In Dakizidda's ego network we can see the ways in which network ties could have affected artistic choices.

I included the seal imagery from Garrison and Root's typology when looking at Dakizidda's ego network and it is in the glyptic evidence, perhaps, that this ego network analysis produced its most interesting findings. No two seals in Dakizidda's ego network are typologically identical and the seals cover a wide variety of style and imagery. Looking specifically at Dakizidda's seal it echoes the seal of his fellow camel driver, Ukbakurna, in a striking manner. Both seals represent lion and bull encounters - although of very different types. Ukbakurna's seal is less reminiscent of the monumental lion-bull emblem and more resonant with a popular image tradition of lions killing ruminants (Figure 6). While Dakizidda's PFS 1532s is a stamp seal and Ukbakurna's PFS 1035 is a cylinder seal, their iconography is in clear dialogue. PFS $1532 \mathrm{~s}$ is, after all, applied three times in a row (Figure 4). It is possible that, as well as trying to represent a journey under constant light, Dakizidda is also trying to use his stamp seal to mimic a cylinder seal or a lion hunt scene, like that of Ukbakurna (Figure 6). From our network analysis we can see that they associated with the same supplier and the same profession - suggesting the plausibility of personal interactions between Dakizidda and Ukbakurna. Perhaps this imitation was competitive emulation or some type of joke amongst camel drivers; (what Root has called 'seal play'); Dakizidda may have playfully wanted to demonstrate the versatility of his seal and its potential to transform itself into an image reminiscent of the dynamic produced by Ukbakurna's lion-attack cylinder seal. While the sample is admittedly too small to draw distinct conclusions, the other individual in this ego network connected with camels, Bawukšamira, is not identified as a camel driver and does not use this motif on his seal, instead using an image of human-animal combat involving a chariot. Maybe these different motifs represent distinctions between 'camel drivers' and individuals who lack this designation. Bawukšamira could also simply have not been part of some seal-based joke or story. By looking at Dakizidda from a network perspective, we can place his seal choice, his sealing practices, and his place at Persepolis in a new framework that considers groups well beyond the royal circle and elucidates a variety of important connections operating at different social levels.

\section{Future research trajectories}

The analysis presented here is only a first step in a broader project. This initial study of Dakizidda highlights an individual with an interesting profession while raising further questions about the nature of camel driving. While certain of the above conclusions could have been reached through more traditional means such as prosopography, a network approach allows for a more holistic picture that can incorporate other research trajectories.

administrator (M. Garrison, 'Seals and the elite at Persepolis: some observations on early Achaemenid Persian art', in Ars Orientalis 21 (1991) 12) while PF 1950 is not sealed. PF 1950, recording the disbursement of grain to camel drivers, records twenty-three men and thirty-three boys as receiving rations. Perhaps this gives us a picture of the size of the camel driving operations at Persepolis. 


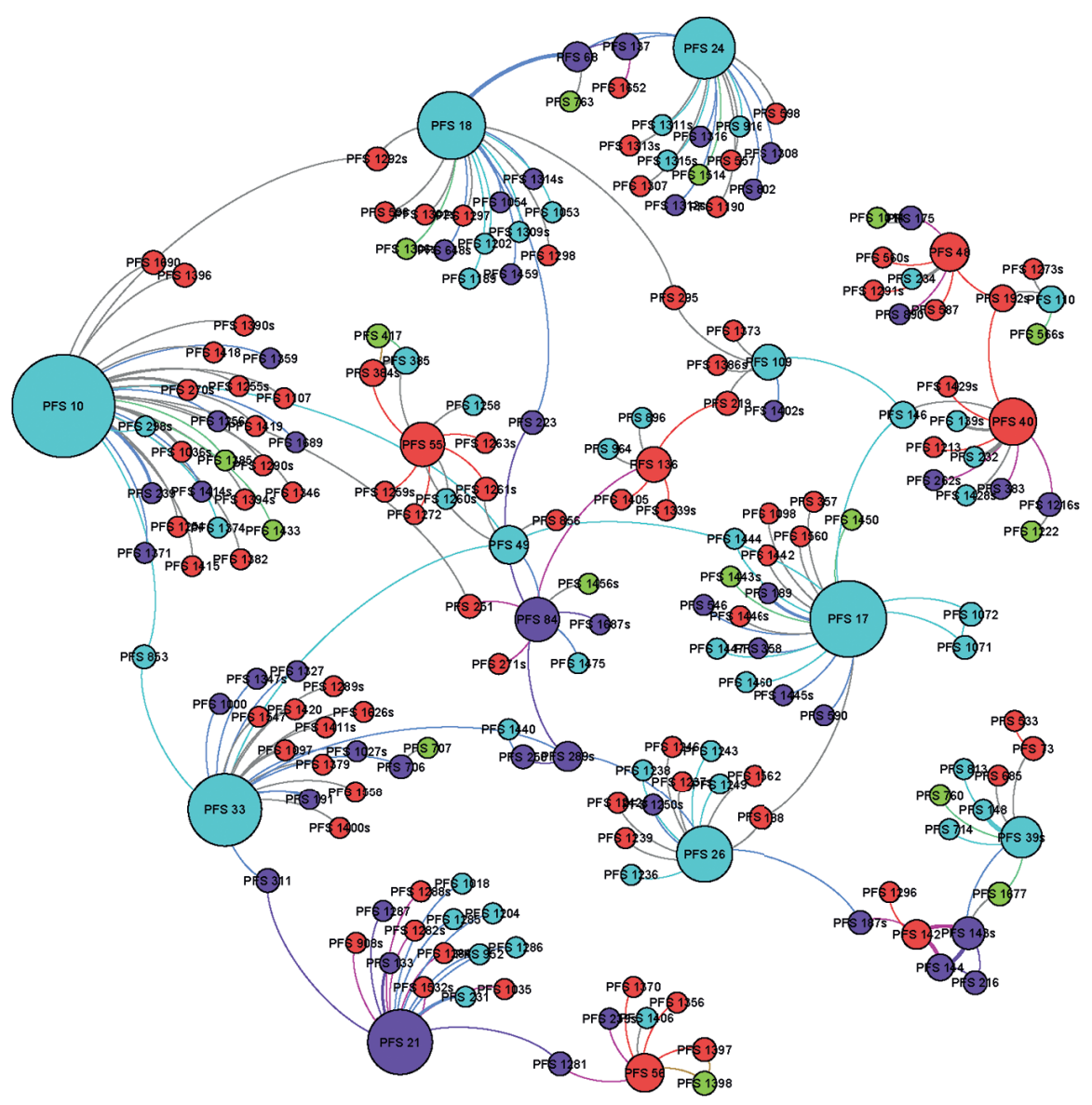

Figure 7: Network visualization of my network of seals and seal-using individuals connected to PFS 1532s. The different colours represent the four basic seal imagery categories into which Garrison and Root have divided their research corpus for analytical and publication purposes (turquoise: scenes of heroic encounter; purple: images of human activity; red: animals, plants, and geometric devices; green: analytically illegible images or destroyed impressions).

Numerous other variables could be incorporated and analysed, such as time, seasonality, prosopographic data, seal type, and seal workshops. In their study of the seals, Garrison and Root organized the seals thematically into basic categories of legible images: scenes of heroic encounter (I); images of human activity (II); and animals, creatures, plants, and geometric devices (III). ${ }^{63}$ Beyond these basic thematic categorizations, Garrison and Root also created a multitiered system of formal criteria to better characterize the seals; this included seal shape, imagery details, inscription details where applicable, and style. ${ }^{64}$ This is best seen in the scenes of heroic encounter, in which one basic representational thematic

\footnotetext{
${ }^{63}$ Garrison and Root, Seals on the Persepolis Fortification Tablets Volume I (n. 3, above) represents the publication of type I seals.

${ }^{64}$ The following discussion is drawn from Garrison and Root, Seals on the Persepolis Fortification Tablets Volume $I$ (n. 3, above) 60-61. Dakizidda's seal will appear in Garrison and Root forthcoming, vol. III.
} 
is presented on over 300 seals in a set of variants that can be categorized. ${ }^{65} \mathrm{I}$ included these different categories and typologies in my social network analysis and created a version of the network of seals and seal-using individuals connected to PFS 1532s where different seal types from Garrison and Root's research are identified in different colours (Figure 7). The seals that have the highest centrality scores, and are therefore the most important in the efficient operation of this network, all fall into the same iconographic category: seals of heroic encounter. These scenes of heroic encounter, however, can be quite variable. Just as looking at Dakizidda's ego network helped inform some aspects of his seal and sealing choices, an examination of the ego networks of these influential seals of heroic encounter allows us to ask whether the imagery of these seals with high centrality scores plays a role in the choices made by those sealing individuals around them. ${ }^{66}$ This could be further nuanced by identifying seals with different elements of Garrison and Root's multitiered system.

Dynamic network analysis, a type of network analysis that takes into account the passage of time, could also provide interesting results for the PF archive, especially since many of the tablet texts are dated. I also hope to incorporate data from the NN tablets, a group of texts that are not part of Hallock's PF corpus. Preliminary research has already shown that this will expand my networks significantly: perhaps there are more camel drivers with lion-bull encounter seals in this expanded corpus. Furthermore, recent work on the Aramaic tablets from Persepolis (PFAT) has revealed that certain PF seals also occur on the PFAT tablets. ${ }^{67}$ The future research trajectories are numerous and promising.

As network analysis has become a more popular method within archaeology and ancient history for examining the interplay of relationships in the past, scholars have been forced to stretch their data to fit into this paradigm. The nature of most historical and archaeological data makes it fundamentally different from the data used in social and behavioural sciences. The wealth of social, economic, and artistic information present on the Persepolis Fortification tablets provides an almost unprecedented tool for populating and analysing the ancient past. The complexity of data, despite being incomplete, is staggering and fits nicely into the parameters of social network analysis. This is particularly true for the non-elites at Persepolis, a group of people often understudied and denied agency in actively affecting the world around them. This initial analysis of the PF corpus implies quite the opposite form this stilted view; non-elites at Persepolis were not only important actors in a variety of spheres at Persepolis, they also played a central role in tying together numerous complex Achaemenid imperial networks (economic, artistic, social) as well as creating their own networks of exchange (again economic, artistic, and social). Alongside kings and courtiers, camel drivers and wine sellers created and maintained the economic and visual systems that drove the Achaemenid imperial project. As social network analysis is brought to bear more fully on the Achaemenid material, I do not doubt that we will get an even better picture of the importance of Dakizidda and his peers as drivers of the flourishing Achaemenid Empire.

\section{IPCAA, University of Michigan}

\footnotetext{
${ }^{65}$ Personal correspondence. The other two volumes (nearing completion) contain a huge range of compositions so the system will operate in a slightly different manner. While the typologies for vols II-III have not been published in advance of the catalogues themselves, Garrison has generously provided me with a database of every legible seal, with the provisional typology of those seals falling outside of vol. I. A few poorly preserved seals remain in fluid state between vols II and III at the moment of writing, but they do not invalidate this demonstration.

${ }^{66}$ With the imminent publication of vols II and III of Garrison and Root's study of the PF seals this type of research will be even easier to operationalize.

${ }^{67}$ Azzoni and Dusinberre, 'Persepolis Fortification Aramaic Tablet seal 0002' (n. 57, above). The seals PFS 17, PFS 48, PFS 124s, PFS 192s, and PFS 1312s occur in Dakizidda’s network as well as the PFAT tablets.
} 